Supporting Information

\title{
Following Structural Changes by Thermal Denaturation using Trapped Ion Mobility Spectrometry - Mass Spectrometry
}

Kevin Jeanne Dit Fouque ${ }^{\dagger}$ and Francisco Fernandez-Lima.., ${ }^{*, \neq}$

† Department of Chemistry and Biochemistry, Florida International University, Miami, FL 33199, United States.

‡ Biomolecular Sciences Institute, Florida International University, Miami, FL 33199, United States.

Corresponding Author

fernandf@fiu.edu

Table of Contents:

Figure S1. TIMS-MS instrument showing the schematic of the temperature-controlled nESI ionization source with the TIMS cell and TIMS operation.

Figure S2. Plot representing the evolution of temperature as a function of time for BSA at $2 \mu \mathrm{M}$ and 25 $\mu \mathrm{M}$.

Figure S3. Native TIMS spectra of the multiply protonated species of BSA monomers, BSA dimers and BSA trimers in native starting solution conditions.

Figure $\mathbf{S}_{4}$. Typical TIMS profiles for the multiply protonated species of BSA obtained at $63{ }^{\circ} \mathrm{C}$.

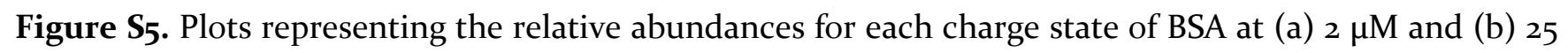
$\mu \mathrm{M}$ as a function of the starting solution temperatures.

Figure S6. Replicates showing the reproducibility of the TIMS profiles as a function od the starting solution temperature for the (a) $[\mathrm{M}+25 \mathrm{H}]^{25+}$ and (b) $[\mathrm{M}+38 \mathrm{H}]^{38+}$ ions. 


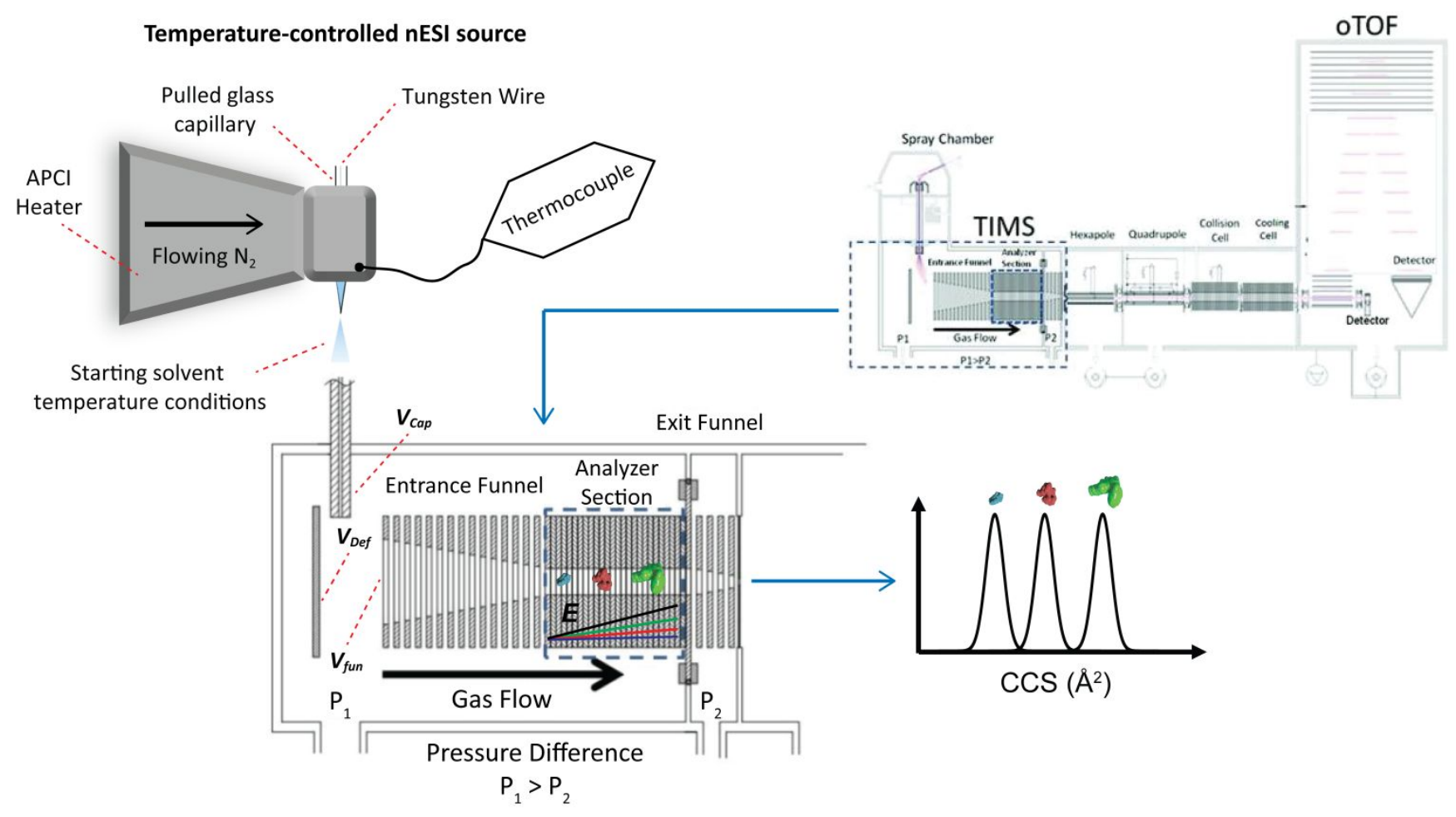

Figure S1. TIMS-MS instrument showing the schematic of the temperature-controlled nESI ionization source with the TIMS cell and TIMS operation. 

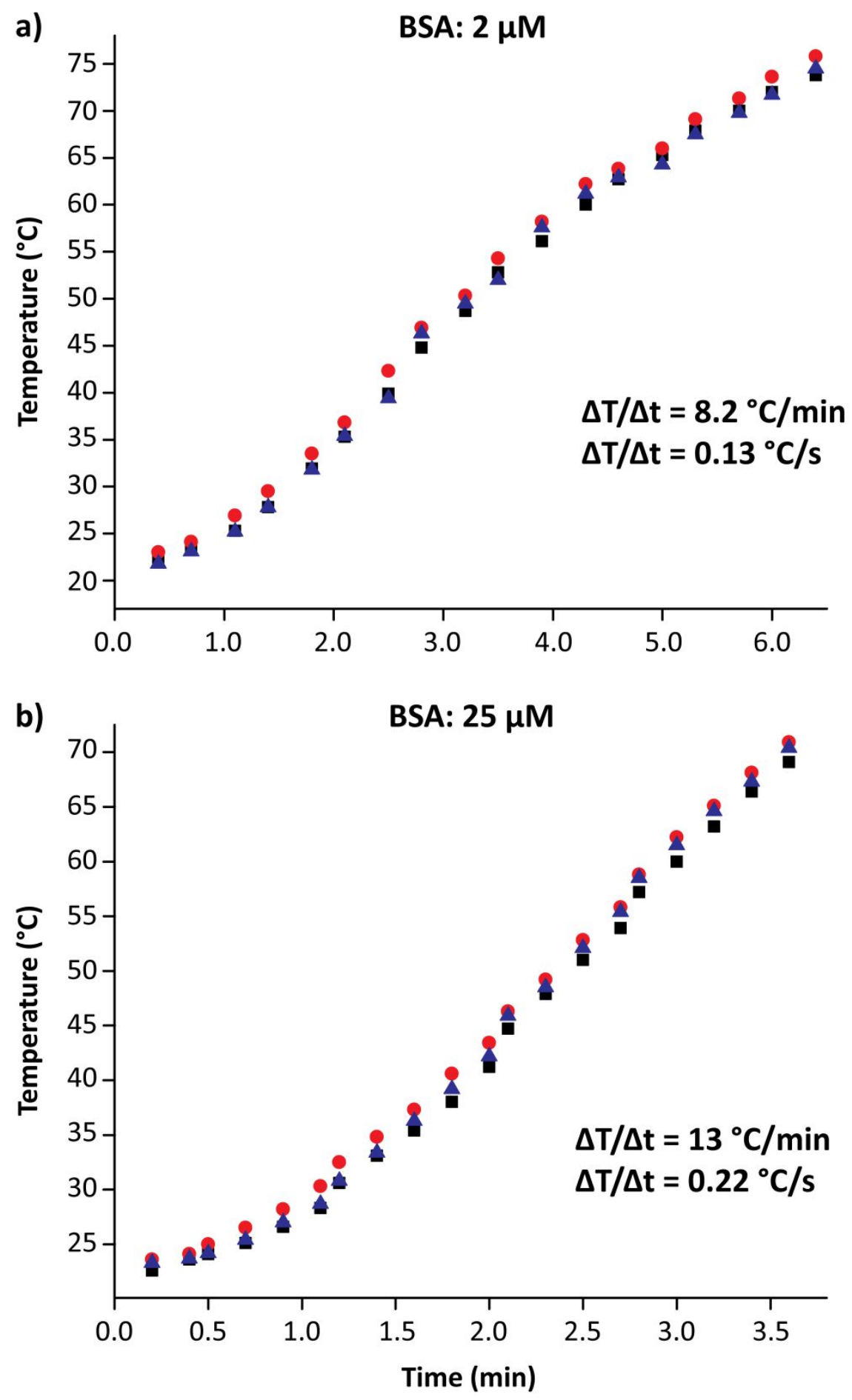

Figure S2. Plot representing the evolution of temperature as a function of time for BSA at (a) $2 \mu \mathrm{M}$ and (b) $25 \mu \mathrm{M}$. The color symbols shows the replicate experiments. 
a) BSA Monomers

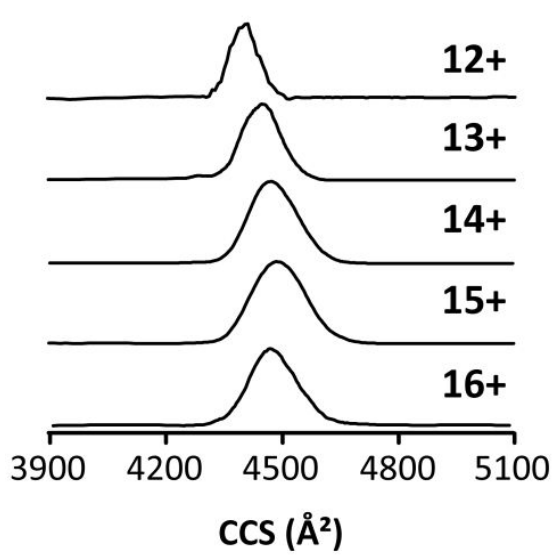

b) BSA Dimers

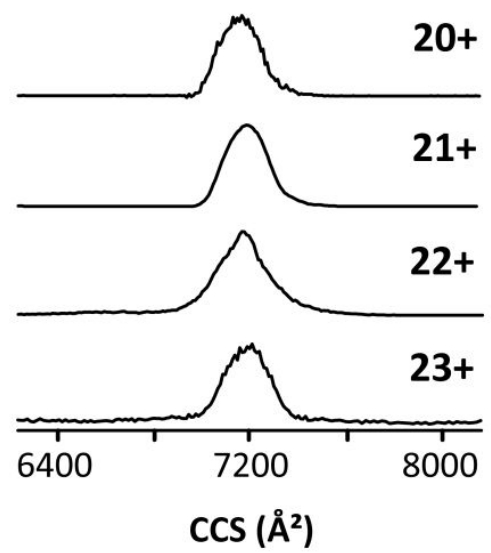

c) BSA Trimers

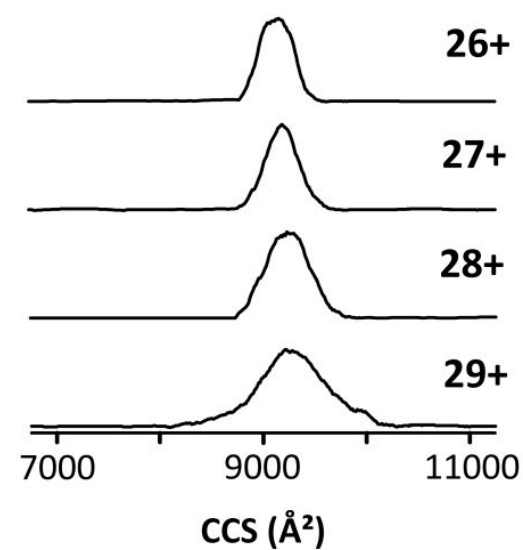

Figure S3. Native TIMS spectra of the multiply protonated species of (a) BSA monomers, (b) BSA dimers and (c) BSA trimers in native starting solution conditions (i.e. $100 \mathrm{mM} \mathrm{NH}_{4} \mathrm{Ac}$ at $23^{\circ} \mathrm{C}$ ). 


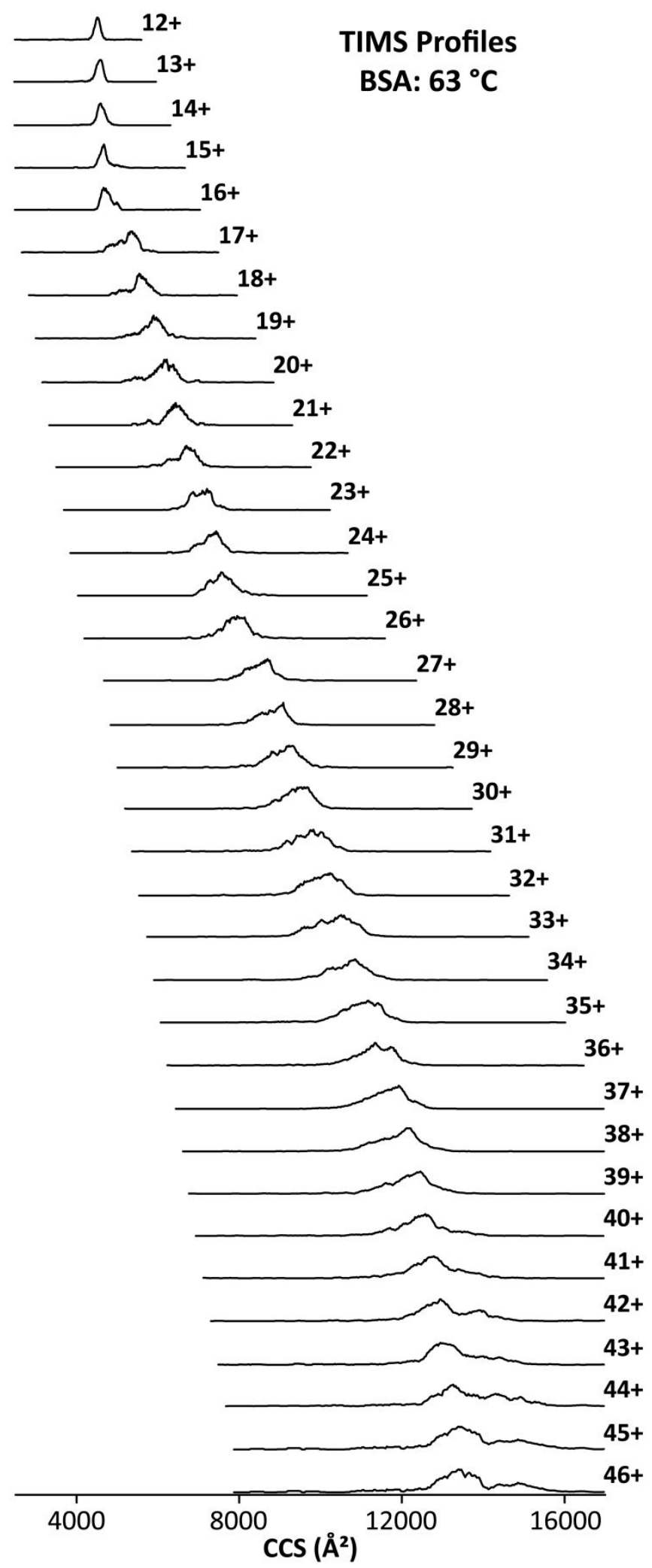

Figure S4. Typical TIMS profiles for the multiply protonated species of BSA obtained at $63{ }^{\circ} \mathrm{C}$. 


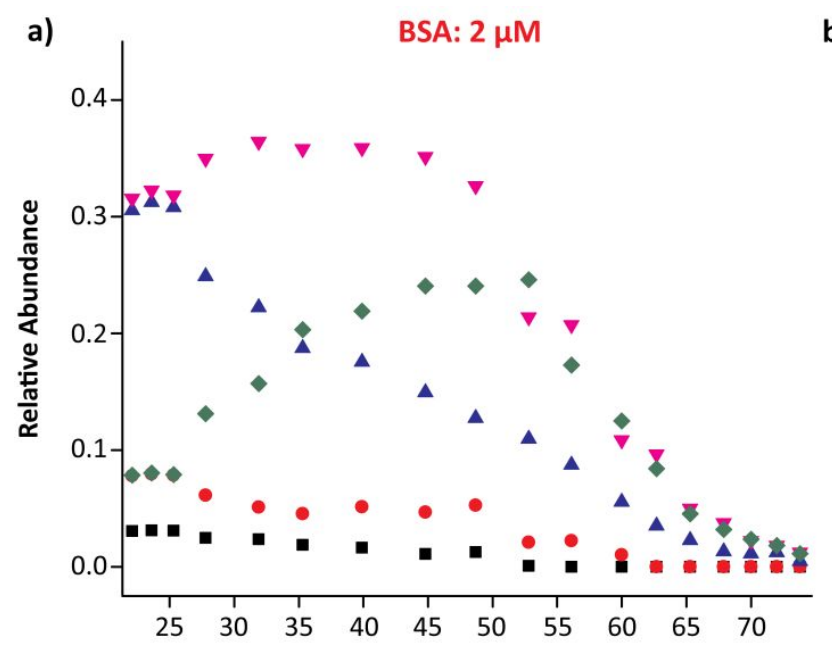

b) $0.4 \quad$ BSA: $25 \mu \mathrm{M}$
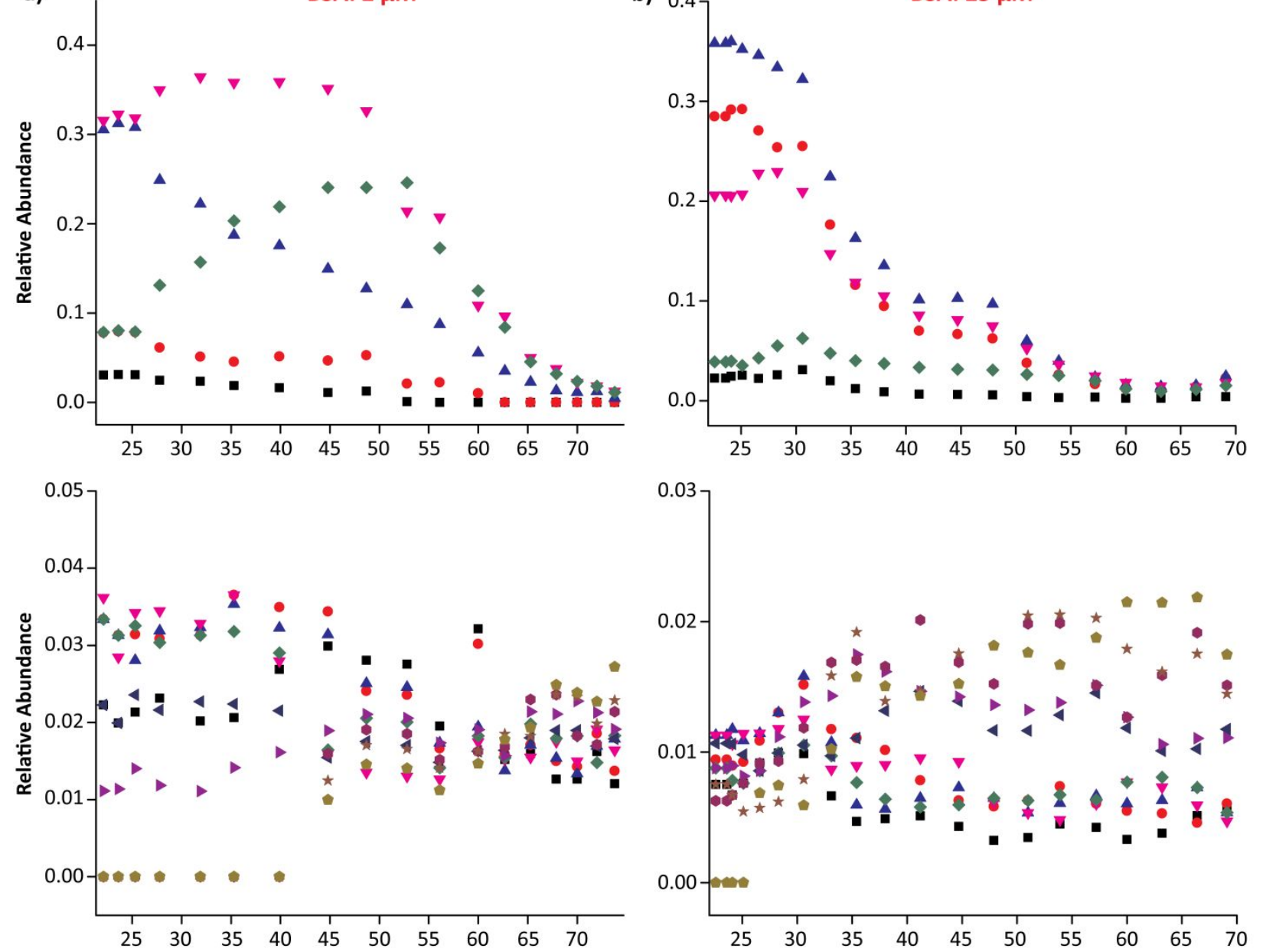

- $12+$

- $13+$

$\Delta 14+$

$\nabla 15+$

$\rightarrow 16+$
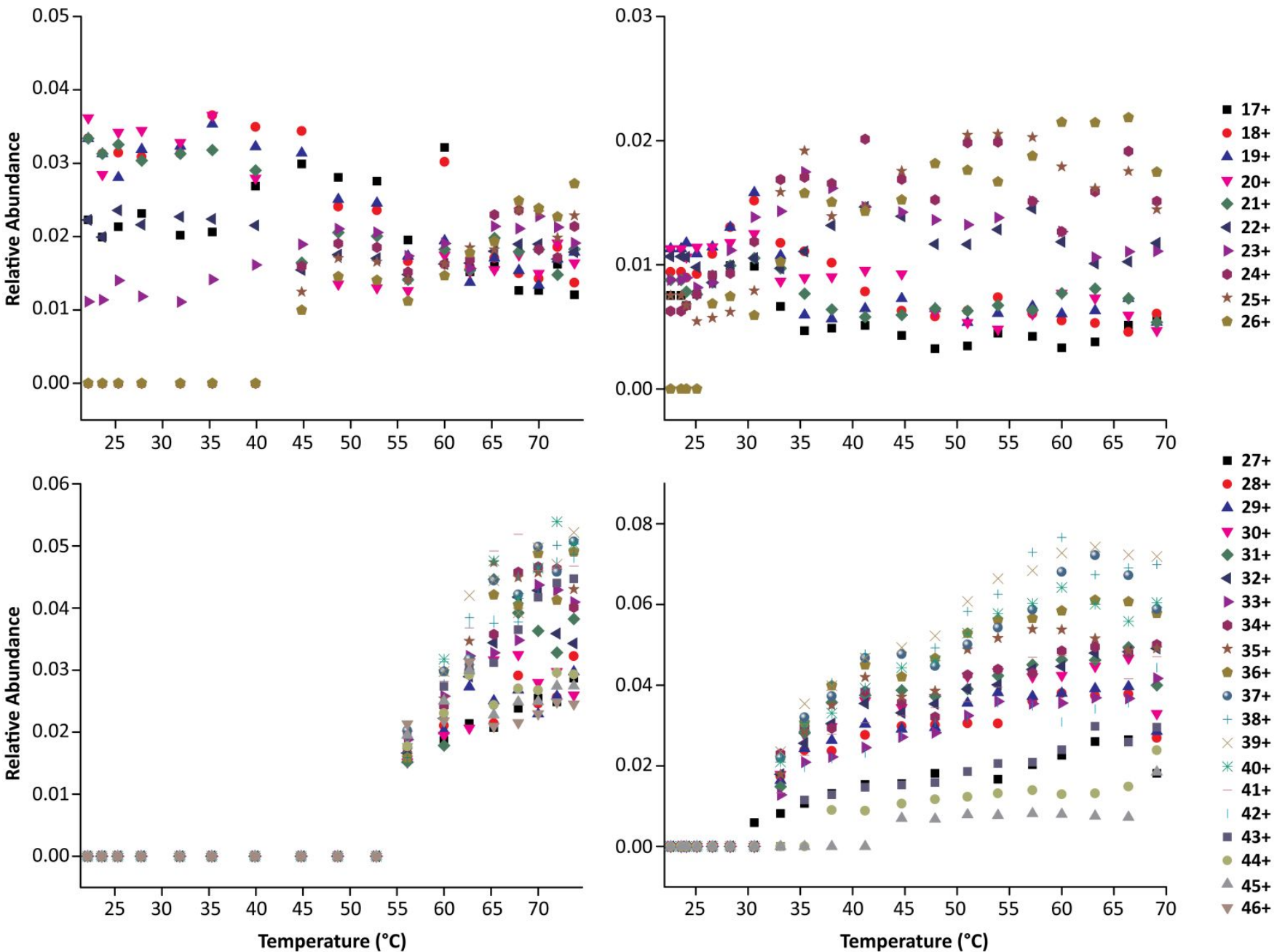

Figure S5. Plots representing the relative abundances for each charge state (12+ to 46+) of BSA at (a) 2 $\mu \mathrm{M}$ and (b) $25 \mu \mathrm{M}$ as a function of the starting solution temperatures. 
a)
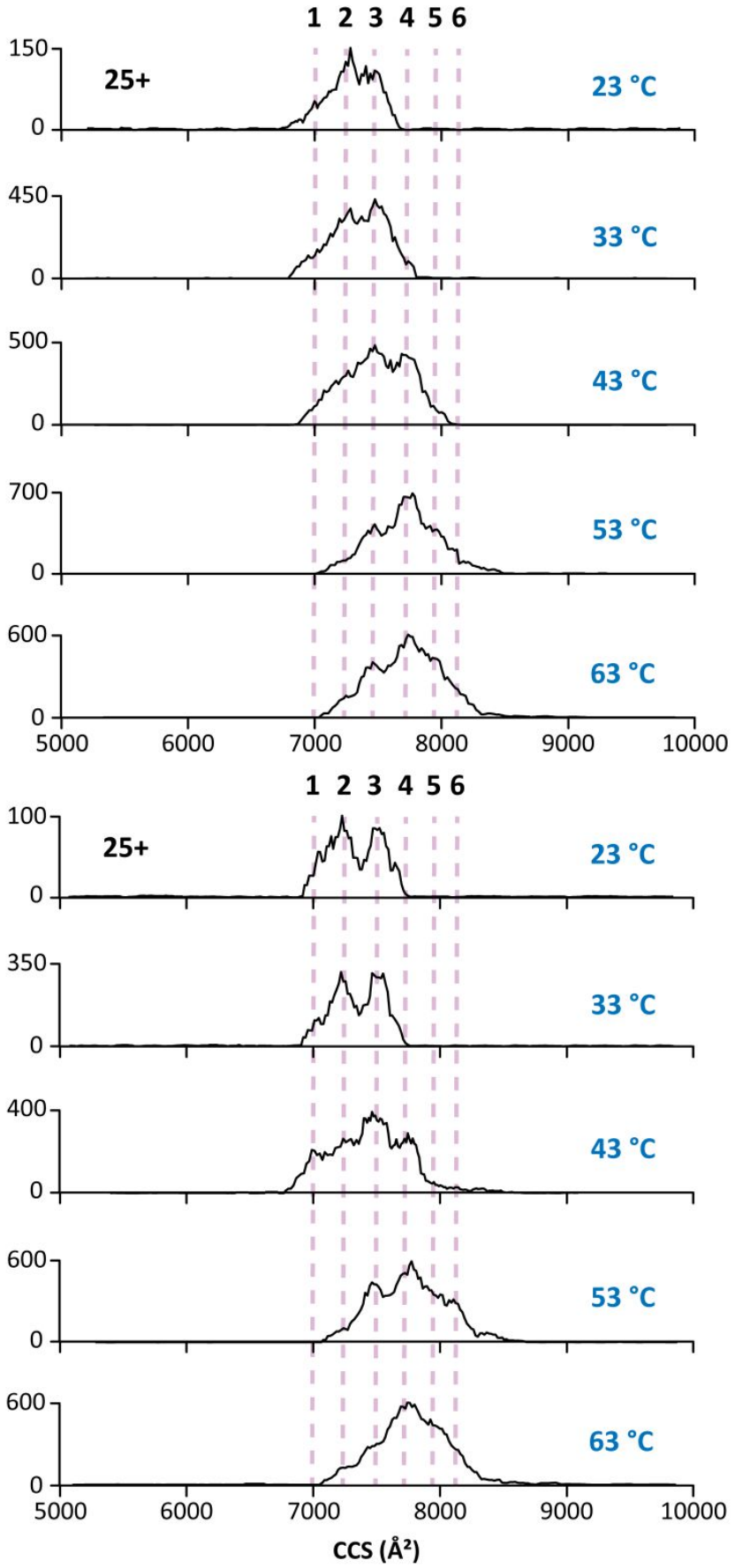

b)
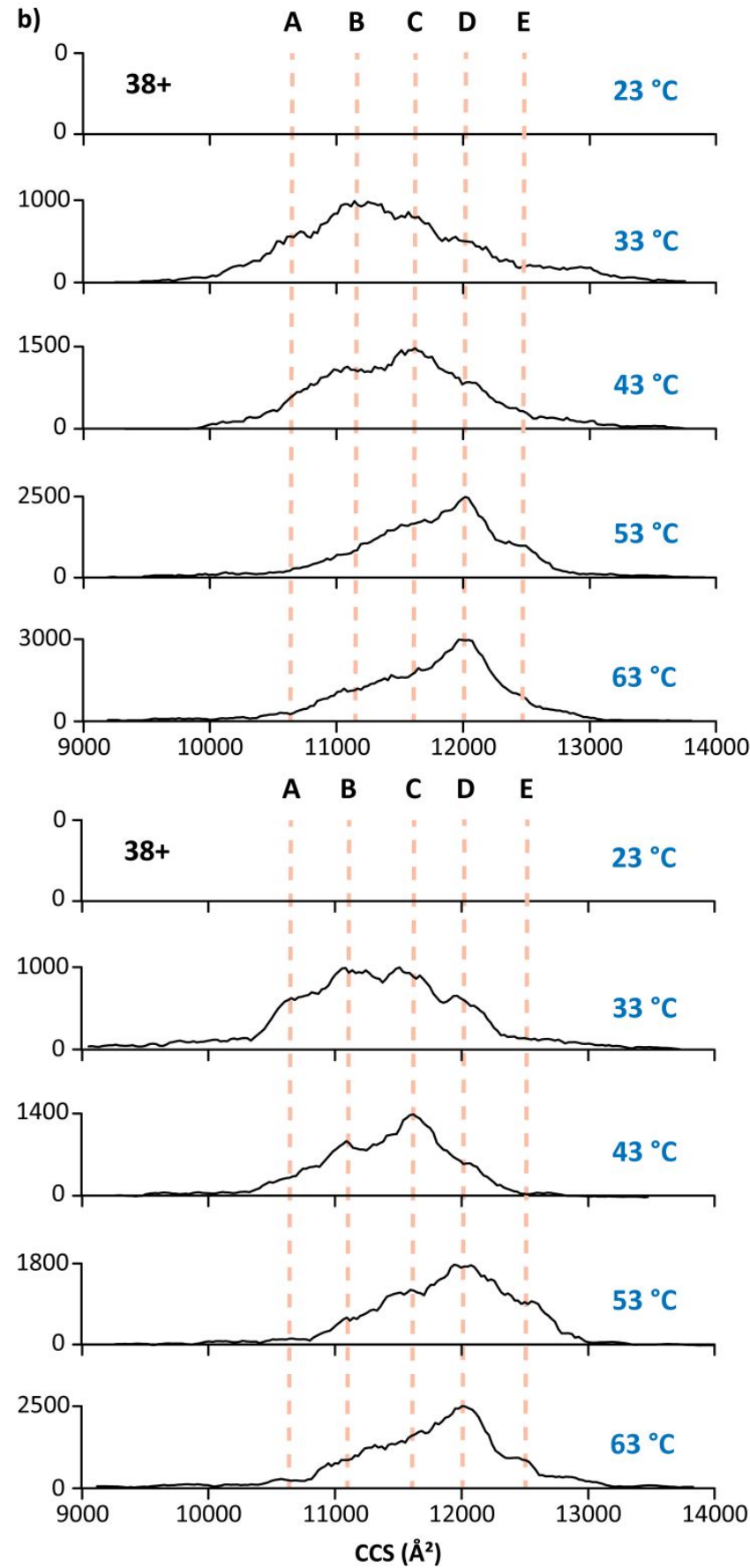

Figure S6. Replicates showing the reproducibility of the TIMS profiles as a function of the starting solution temperature for the (a) $[\mathrm{M}+25 \mathrm{H}]^{25+}$ and (b) $[\mathrm{M}+38 \mathrm{H}]^{38+}$ ions. 